\title{
Epidemiology, pathogenesis, and management of takotsubo syndrome
}

\author{
Shams Y-Hassan ${ }^{1} \cdot$ Per Tornvall $^{2}$
}

Received: 2 June 2017 / Accepted: 31 August 2017 / Published online: 15 September 2017

(C) The Author(s) 2017. This article is an open access publication

\begin{abstract}
Takotsubo syndrome is a recently recognized acute cardiac disease entity with a clinical presentation resembling that of an acute coronary syndrome. The typical takotsubo syndrome patient has a unique circumferential left (bi-) ventricular contraction abnormality profile that extends beyond a coronary artery supply territory and appears to follow the anatomical cardiac sympathetic innervation. The syndrome predominantly affects postmenopausal women and is often preceded by emotional or physical stress. Patients with predisposing factors such as malignancy and other chronic comorbidities are more prone to suffer from takotsubo syndrome. The pathogenesis of takotsubo syndrome is elusive. Several pathophysiological mechanisms involving myocardial ischemia (multivessel coronary artery spasm, microvascular dysfunction, aborted myocardial infarction), left ventricular outlet tract obstruction, blood-borne catecholamine myocardial toxicity, epinephrine-induced switch in signal trafficking, and autonomic nervous system dysfunction have been proposed. The syndrome is usually reversible; nevertheless, during the acute stage, a substantial number of patients develop severe complications such as arrhythmias, heart failure including pulmonary edema and cardiogenic shock, thromboembolism, cardiac arrest, and rupture. Treatment of precipitating factors, predisposing diseases, and complications is fundamental during the acute stage of the
\end{abstract}

Per Tornvall

per.tornvall@ki.se

1 Department of Cardiology, Karolinska Institutet at Karolinska University Hospital, Solna, Sweden

2 Department of Clinical Science and Education Södersjukhuset, Karolinska Institutet, Sjukhusbacken 10, 11883 Stockholm, Sweden disease. The epidemiology, pathogenesis, and management of takotsubo syndrome are reviewed in this paper.

Keywords Takotsubo $\cdot$ Broken heart syndrome $\cdot$ Acute coronary syndrome $\cdot$ Neurogenic stunned myocardium . Left ventricle ballooning

\section{Introduction}

Takotsubo syndrome (TS), also known as broken heart syndrome or neurogenic stunned myocardium, is a recently recognized acute cardiac disease entity [1]. The term takotsubo (tako $=$ octopus, tsubo $=$ a pot) was introduced by Sato and Dote in 1990 and 1991 to describe the left ventricular silhouette during systole in five patients presenting with clinical features of myocardial infarction but without obstructive coronary artery disease [2, 3]. The syndrome has a clinical and electrocardiographic presentation resembling that of an acute coronary syndrome (ACS). The main characteristic feature of TS is the regional left ventricular wall motion abnormality (LVWMA) with a peculiar circumferential pattern resulting in a conspicuous ballooning of the left ventricle during systole (Fig. 1a, b). The LVWMA extends beyond the coronary artery supply regions and is reversible with almost complete resolution of ventricular dysfunction in hours to weeks (Fig. 1c, d). The LVWMA may be localized to the apical, midapical, midventricular, midbasal, or basal (Fig. 2) segments of the left ventricle [1]. A focal or global left ventricular contractile abnormality has also been reported $[4,5]$. The right ventricle is involved in about one third of the TS patients [6]. The syndrome is preceded by a trigger factor in about $70 \%$ of patients [4]. Emotional triggers such as death of a close relative or acute grief may trigger the syndrome and 

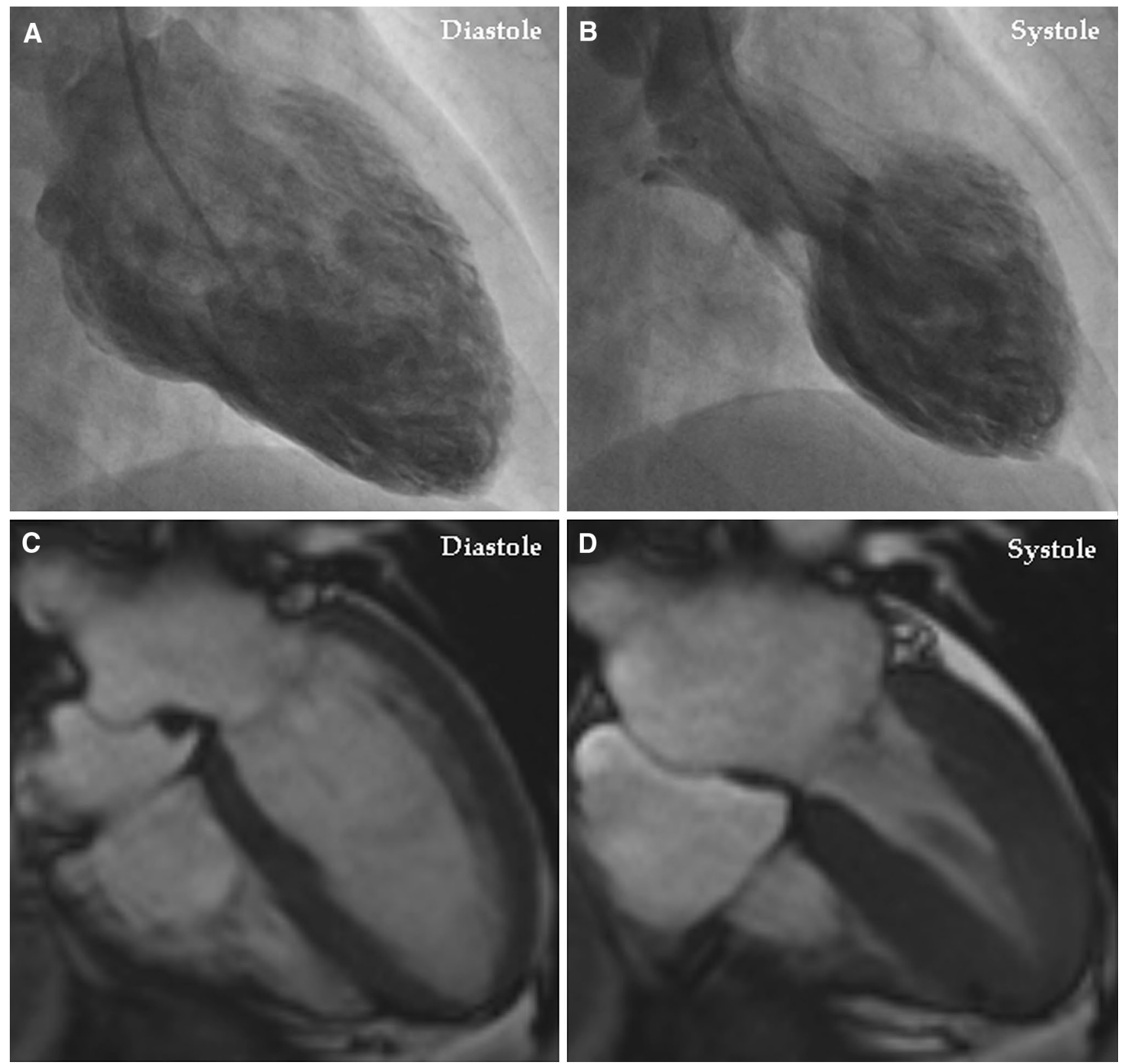

Fig. 1 Left ventriculography during the acute stage of takotsubo syndrome shows typical midapical ballooning during systole (a diastole; b systole). Cardiac magnetic resonance imaging 4 days after left ven-

hence the term broken heart syndrome [7]. Innumerable physical triggers, extending from serious diseases such as intracranial hemorrhages and sepsis to physiological processes such as sexual intercourse and pregnancy, may also trigger the syndrome [8]. Recently, the Heart Failure Association of the European Society of Cardiology in a position statement from the task force on TS introduced the terms primary and secondary TS [9]. In primary TS, triculography shows complete normalization of the left ventricular function (c diastole; $\mathbf{d}$ systole)

acute cardiac symptoms are the primary reason for seeking acute medical care. In secondary TS, the syndrome occurs in patients already hospitalized for a medical or surgical condition. The authors also introduced new diagnostic criteria for TS. Compared to the Mayo Clinic diagnostic criteria for TS [10], which has been adopted for many years, pheochromocytoma is no longer an exclusion criterion for TS. 
Fig. 2 An emotional or a physical trigger in predisposed individuals may result in diverse left ventricular contraction patterns (midapical, apical, midventricular, midbasal, basal, focal, and global). The figure is modified from Y-Hassan S and De Palma R [1] with copyright permission

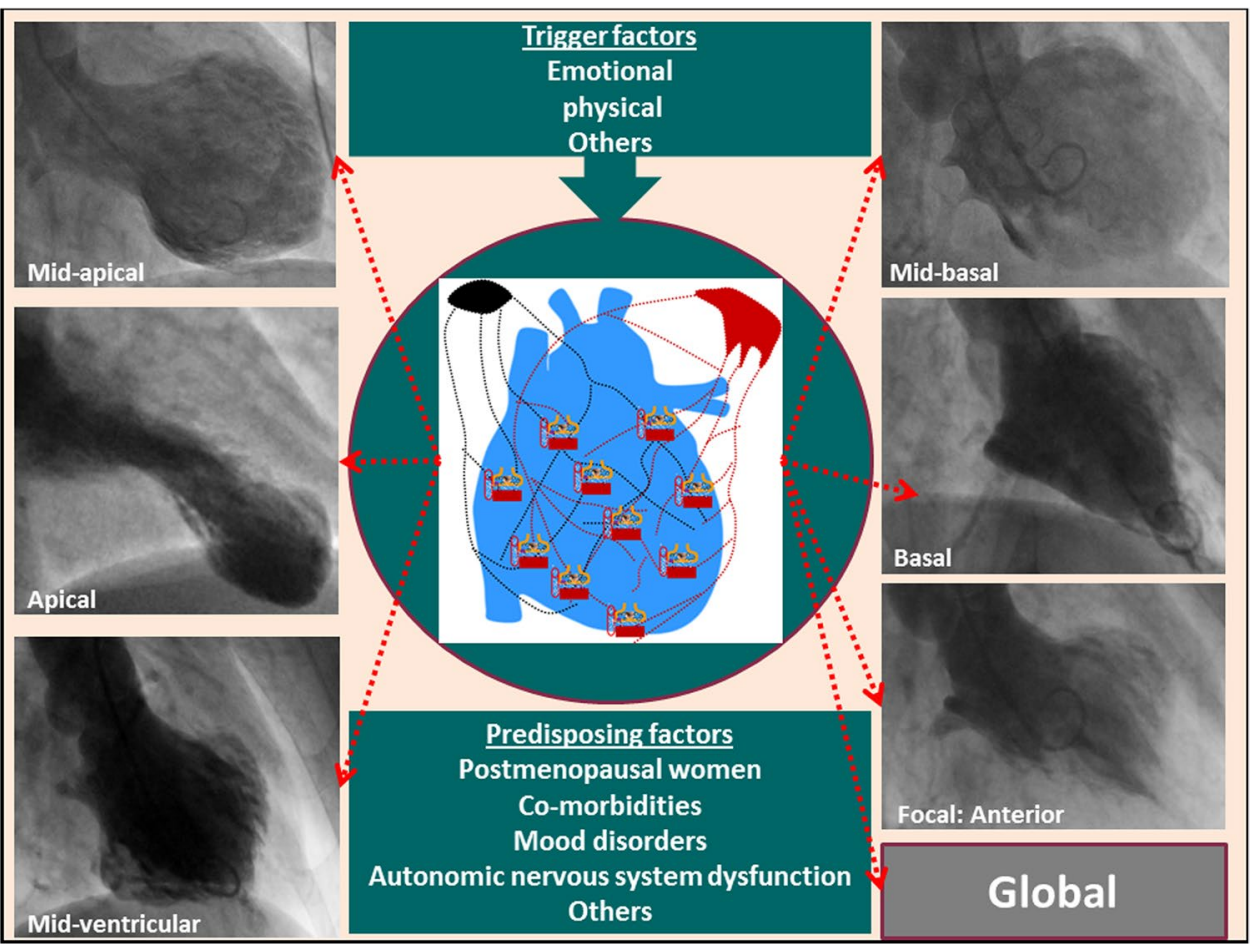

\section{Epidemiology}

Prior to the introduction of the term takotsubo, the syndrome existed under different diagnoses. Since the introduction of the Japanese term takotsubo in 1990 [2], the syndrome has been increasingly recognized in almost all countries of the six continents of the world. TS has been reported in a variety of races but according to some reports, it is uncommon in Hispanics and African Americans [11]. The prevalence of TS has been reported to be approximately $2 \%$ (up to $10 \%$ if only women are considered) of all patients presenting with clinical manifestation of ACS [12]. The prevalence is underestimated and the main reason for this is unawareness of the disease. However, with increasing awareness and more widespread access to early invasive coronary angiography, TS is now recognized more frequently. Minhas et al. [13] reported on a significant increase in the incidence of TS from 2006 to 2012. In that study, the incidence of TS increased almost 20 times during the time-period (Fig. 3). Similarly, a study by Murugiah et al. [14] showed that hospitalization rates for TS are increasing. In that study, the incidence of primary TS increased from 2.3 hospitalizations per 100,000 person-years in 2007 to 7.1 in 2012 . The corresponding incidence for "secondary TS" increased from 3.4 hospitalizations per 100,000 person-years in 2007 to 10.3 in 2012. Studies on TS from different parts of the world have reported that $85-90 \%$ of the patients with TS are women, aged $65-70$ years $[8,9]$. Of 1750 patients with TS, recently

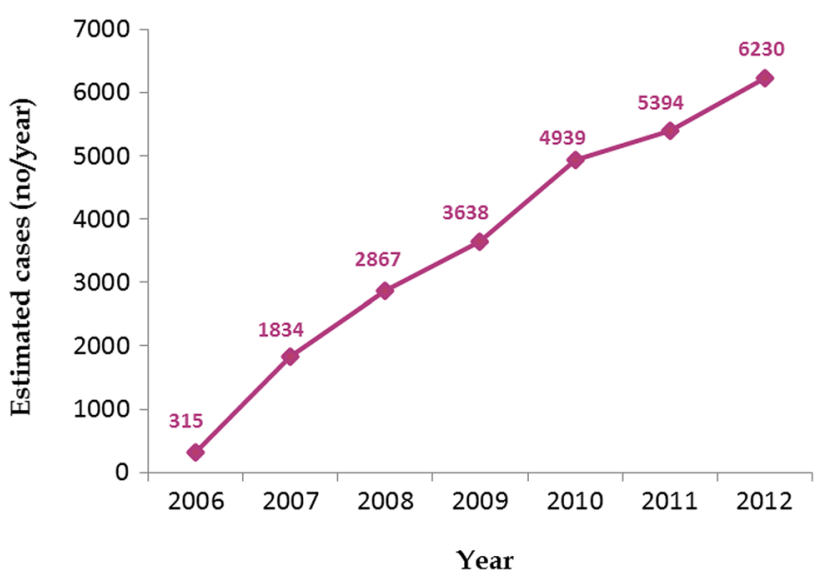

Fig. 3 Trends in reported incidence of takotsubo syndrome from 2006 to 2012. Modified from a table by Minhas AS, Hughey AB, Kolias TJ [13]

reported by Templin et al. [4], 89.8\% were women with a mean age of 67 years. However, the syndrome has been reported in both genders and in all age groups and even in children $[4,8,9]$. The prevalence of affected men with TS is increased when the syndrome is triggered by physical stress as severe critical medical illnesses $[15,16]$. The syndrome may recur and the recurrence rate of TS has ranged from 0 to $22 \%$ [4, 12]. In patients with pheochromocytoma-triggered TS, a recurrence rate of $17.7 \%$ has been reported [15], which is most probably due to undiagnosed pheochromocytoma where the trigger remains. Singh et al. 
[17] reported that the annual recurrence rate was $1.5 \%$ and that the cumulative incidence of recurrence was $1.2 \%$ at 6 months and $5 \%$ at 6 years.

\section{Pathophysiology}

Several pathophysiological mechanisms for the development of TS have been proposed. The pathophysiology of TS is complex and may be multifactorial. The main proposed mechanisms are myocardial ischemia, left ventricular outlet tract obstruction (LVOTO), blood-borne catecholamine myocardial toxicity, epinephrine-induced switch in signal trafficking, and autonomics nervous system dysfunction with sympathetic nervous system hyperactivation including local cardiac sympathetic disruption and norepinephrine seethe and spillover.

\section{Myocardial ischemia}

\section{Multivessel coronary artery spasm}

When Sato and Dote introduced the term takotsubo in 1990 $[3,18]$ to describe the left ventricular silhouette during systole, they deemed the left ventricular dysfunction as myocardial stunning due to simultaneous multivessel coronary vasospasm. This was based on the fact that the investigators demonstrated spontaneous multivessel coronary vasospasm at coronary angiography in two patients and observed coronary spasm in two further patients after ergonovine administration. In subsequent series, the prevalence of coronary vasospasm has been variable. Spontaneous coronary vasospasm was reported in 5-10\%, which implies that the majority of the patients had no spontaneous coronary vasospasm [12]. Provocation-induced coronary vasospasm has been reported in a limited number of patients in the acute phase of TS. In a review of nine studies, provocation testing could induce coronary vasospasm in only 34 of 123 patients (28\%) [12]. In addition to the absence of spontaneous or provocation-induced vasospasm in most cases, LVWMAs with an apical-sparing pattern argue against the multivessel coronary spasm hypothesis in causing TS. Furthermore, dobutamine, which is a vasodilator with minimum vasospastic effects, has been reported to induce TS [19]. Likewise, epinephrine which also has a dominant coronary vasodilatory effect, has been reported to induce TS [19, 20].

\section{Microvascular dysfunction}

Microvascular dysfunction has been advocated by several investigators as a possible pathophysiological mechanism of LVWMA in TS [21]. Coronary angiography reveals normal coronary arteries in the majority of patients with TS [4]. One important limitation of coronary angiography is its inability to visualize the coronary microcirculation. Surrogate noninvasive and invasive techniques have been used to study the microcirculation and the findings may support involvement of the coronary microcirculation in the pathogenesis of TS. Studies using semiquantitative invasive techniques as thrombolysis in myocardial infarction (TIMI) frame count, corrected TIMI frame count (CTFC), TIMI myocardial perfusion grade (TMPG), and coronary flow reserve (CFR) have shown conflicting results. By assessing TIMI frame count, Fazio et al. [22] reported slow coronary flow in 23 of 24 patients with TS during the acute stage. However, the authors observed some findings which argue against the role of microvascular dysfunction, as only nine patients had slow flow in all three epicardial coronary arteries. In another study, Sharkey et al. [23] did not find significant differences in TIMI frame count measurements in 59 patients with TS compared with controls.

Noninvasive methods such as Doppler transthoracic echocardiography (TTE) and myocardial contrast echocardiography (MCE) can provide analysis of both LVWMA and coronary flow [21]. Studies using these noninvasive techniques have shown lower myocardial blood flow in dysfunctional left ventricular segments compared with left ventricular segments showing normal wall motion in the acute phase in patients with TS $[21,24]$. TTE-CFR has also been used to study coronary flow in the acute phase of the disease with similar results [21]. There are a few studies performed after the acute stage of TS. In a study of 22 TS patients 1 year after the acute TS event, Collste et al. [25] could not show decreased TTE-CFR in the left anterior descending artery when compared with healthy controls during high-dose dobutamine administration, indicating that the microvascular dysfunction seen during the acute stage may be a secondary phenomenon.

\section{Aborted myocardial infarction caused by a transient thrombosis in a long wrap-around left anterior descending $\operatorname{artery}(L A D)$}

In a study of five patients with TS, Ibanez et al. [26] reported disrupted atherosclerotic plaques in a long wrap-around LAD when studied by intravascular ultrasound (IVUS). In contrast, other investigators [27, 28] could not confirm disrupted atherosclerotic plaques in TS patients with IVUS performed during the acute stage. The apical-sparing patterns in midventricular and basal types of TS argue against aborted myocardial infarction in a long wrap-around LAD as a cause of TS. The apical-sparing patterns also argue against myocardial bridging with systolic compression of LAD as a cause [29-31]. Furthermore, in 73\% of patients with TS, the course of LAD does not fulfil the criteria of long wraparound LAD [32]. Long-lasting (hours or even days) ST 
segment elevation in patients with TS also challenges the hypothesis of aborted myocardial infarction, in which rapid resolution of ST elevation after reperfusion is an important feature [33, 34].

Another feature in TS, which could not be explained by the proposed ischemia hypothesis, is the cardiac myocyte histopathology. Contraction band necrosis is a characteristic histopathologic feature in TS that is distinct from coagulation necrosis, the fundamental histopathological sign in myocardial infarction [35-37]. Worth mentioning is the fact that TS and chronic obstructive coronary artery disease may coexist [4]. Furthermore, ACS caused by acute thrombotic coronary occlusion or spontaneous coronary artery dissection with associated severe chest pain is a major stress factor and, as any other physical stress factor, may trigger TS [38-40].

\section{Left ventricular outlet tract obstruction (LVOTO)}

LVOTO has been observed in patients with TS. This may cause hypotension and may be one of the causes of cardiogenic shock in TS. El Mahmoud et al. [41] demonstrated a relatively high prevalence of LVOTO $(25 \%)$ in a study of 32 TS patients. They suggested that patients with a localized sigmoid septum and a small left ventricle may be predisposed to severe midcavity obstruction during periods of excessive sympathetic stimulation. Theoretically, this LVOTO could result in apical subendocardial ischemia with resulting ballooning due to a large pressure gradient between the apex and base of the left ventricle. However, the majority of patients with TS do not have LVOTO [41]. Furthermore, LVOTO does not provide a reasonable explanation for the apical-sparing and basal patterns of TS, which is found in substantial numbers of patients [15, 20, 29, 30, 42, 43]. Furthermore, the right ventricular involvement seen in almost one third of the patients with TS cannot be explained by LVOTO [6, 44]. The LVOTO observed in some patients with TS is most likely a complication rather than an underlying cause of the LVWMA.

\section{Blood-borne catecholamine myocardial toxicity}

Blood-borne catecholamine myocardial toxicity has been suggested as one of the pathophysiological mechanisms of TS. This is based on the history of emotional stress preceding the disease onset in many patients with TS [8]; the report of extremely high plasma catecholamine levels in TS patients in one study [45]; the occurrence of TS in patients with pheochromocytoma [15]; and the induction of TS by therapeutic and accidental administration of epinephrine, norepinephrine, and other catecholamine inotropics [20, 46]. However, this hypothesis is challenged by other findings in patients with TS. Clinically, a considerable number of patients with TS lack a history of antecedent emotional or physical triggering stress factor $[8,47]$. Extremely high plasma catecholamine levels have not been reproduced in other studies [48-50]. Furthermore, the circumferential pattern of LVWMA with sparing of basal or apical parts of the left ventricle (Fig. 2) indicates that blood-borne catecholamines (if increased as in pheochromocytoma) are not primarily causing TS but rather act a trigger factor for the cardiac sympathetic system to cause TS [19].

\section{Plasma cortisol and TS}

On one hand, TS triggered by adrenal adenocarcinoma secreting high cortisol levels has been reported [51]. On the other hand, TS triggered by secondary adrenal insufficiency in ACTH isolated deficiency has also been reported [52]. Evidence for a causal relation between plasma cortisol and TS is lacking. Madhavan et al. [48] reported no differences between plasma cortisol levels in patients with TS and patients with ST elevation myocardial infarction. The 24-h urine free cortisol levels were normal in all patients with TS. These results were confirmed by another study reported by Kastaun et al. [53]. Smeijers et al. investigated the hypothalamic-pituitary-adrenal (HPA) axis (adrenocorticotropic hormones and cortisol) in patients with a past history of TS. They found the expected HPA responses to mental stress with no difference between TS and healthy controls [54].

\section{Epinephrine-induced switch in signal trafficking}

Lyon et al. [55] in 2008 hypothesized that high levels of circulating epinephrine trigger a switch in the intracellular signal trafficking from Gs (stimulatory) to Gi (inhibitory) protein signaling through the B2 adrenoreceptor (B2AR). They suggested that this change in signaling was negatively inotropic and that the effect was greatest at the apical myocardium, explaining the apical ballooning seen in TS. In a rat model of TS, Paur et al. [56] reported that an injection of a high-concentration bolus dose of epinephrine triggered left ventricular apical ballooning. They suggested biased agonism of epinephrine for Gs at low concentrations compared with $\mathrm{Gi}$ at high concentrations explained the LVWMA observed in TS. However, there are clinical findings in TS patients that challenge this suggested pathophysiological mechanism. Paur et al. based their suggestion on the presumed fact that in patients with TS, there will be an extreme surge of epinephrine in response to the triggering stressor or coexisting medical condition. However, extremely high plasma concentrations of catecholamines have only been seen in one study [45], whereas other studies have shown normal or near normal plasma catecholamine levels [48-50]. Paur et al. reported in their study only apical ballooning after a high-concentration bolus epinephrine injection. In 
contrast, Redfors et al. [57] induced mainly the basal type of TS during injection of epinephrine in rats. Furthermore, other investigators $[15,20,42,43]$ reported on apical-sparing patterns of TS in almost $50 \%$ of patients when triggered by epinephrine administered either therapeutically or accidentally or TS triggered by pheochromocytoma. Consequently, substantial evidence argues against a direct causal effect of epinephrine in TS; nevertheless, epinephrine may act as a trigger factor for TS.

\section{Hyperactivation of the sympathetic nervous system in the pathogenesis of TS}

Investigators $[1,58,59]$ have provided substantial evidence for involvement of the sympathetic nervous system, including hyperactivation and disruption of local cardiac sympathetic nerve terminals and norepinephrine seethe and spillover, in the pathophysiology of TS (Fig. 4). The occurrence of the syndrome after emotional triggering events, the myocardial stunning with a peculiar circumferential pattern, which may follow the local cardiac sympathetic nerve distribution, the histopathological findings of contraction band necrosis, and the evidence for catecholamine myocarditis with myocardial edema are among supportive data for the involvement of the local cardiac sympathetic nervous system in the pathophysiology of TS [60] discussed below.

\section{Evidence for sympathetic nervous system hyperactivation-disruption in TS}

Emotional stressors The deep anguish that arises from bereavement and induces TS in an individual argues for an excessive sympathetic stimulation of the myocardium, likely mediated via the brain. Anecdotal histories related to death induced by emotions have been described for hundreds of years [2]. The term "broken heart" was used under circumstances in which life experiences could become capable of causing cardiac death. In 1967, Rees and Lutkins

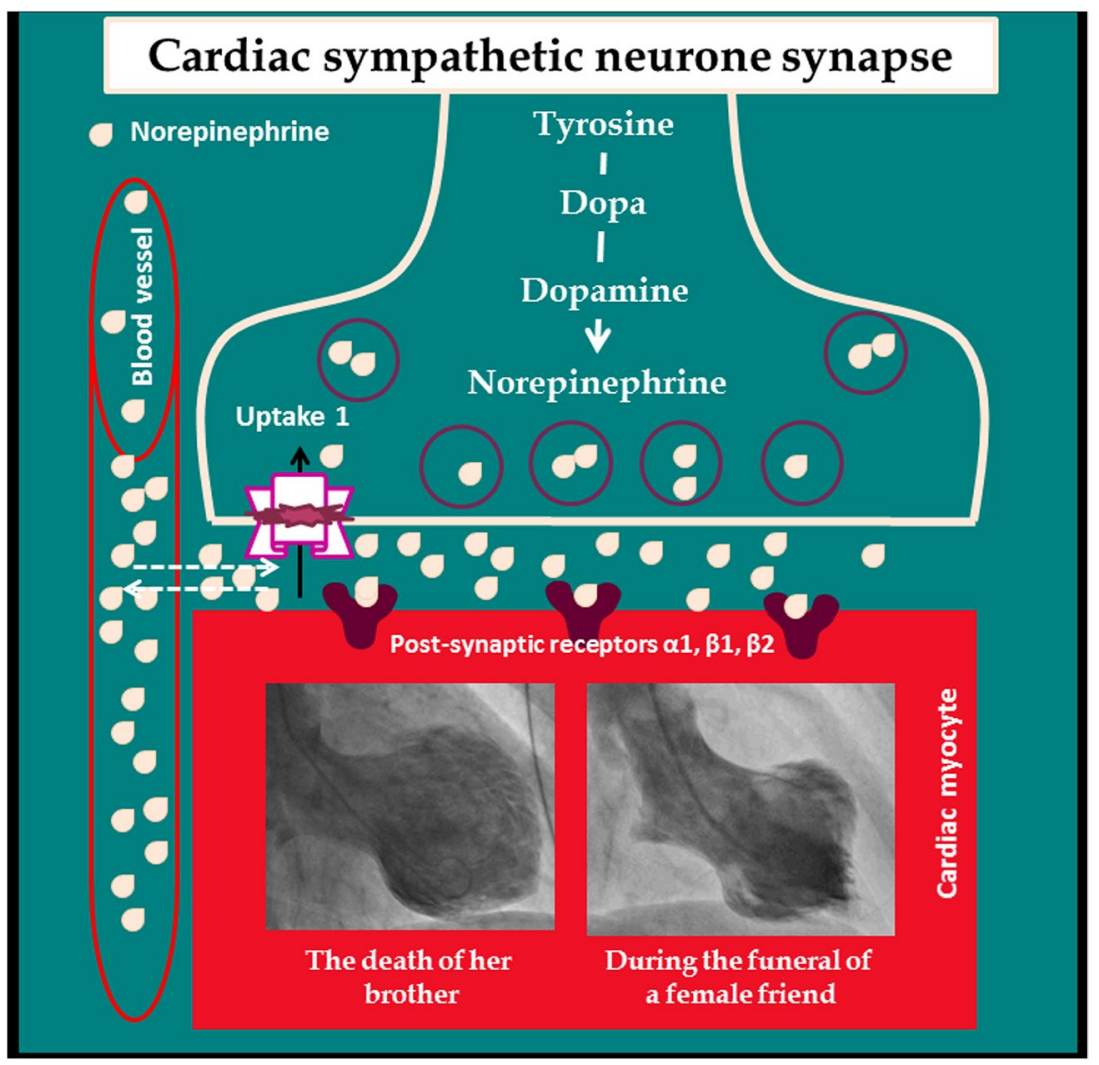

Fig. 4 Illustration of cardiac sympathetic hyperactivation disruption at the cardiac sympathetic neurone synapse. Under normal physiologic conditions, when a cardiac sympathetic nerve is stimulated, norepinephrine stored in granules in the presynaptic nerve terminals is released into the synaptic cleft. Norepinephrine stimulates postsynaptic alpha and beta adrenergic receptors on cardiac myocytes, activating downstream effector pathways. In takotsubo syndrome, local cardiac sympathetic overactivation-disruption results in excess and spillover of norepinephrine, causing regional myocardial stunning, as depicted by left ventriculography of two cases showing midapical and midventricular TS. Norepinephrine excess may also inhibit the uptake-1 region, leading to a decrease of norepinephrine reuptake and increase wash-out of norepinephrine into the circulation. The figure is modified from Y-Hassan S. and De Palma R. [1] with copyright permission 
[61] reported on a significant increase in death rates among bereaved close relatives. After the introduction of the term takotsubo in 1990, case series of emotionally triggered TS were reported [47, 62]. In larger observational studies, TS triggered by emotions comprises more than one fourth (27.7\%) of the patients reported with TS [4].

Acute brain diseases and TS Acute intracranial diseases such as intracranial and subarachnoid hemorrhage, thrombotic stroke, epilepsy, and others have been reported to induce TS [63-67]. This strongly suggests the involvement of the sympathetic nervous system in the pathophysiology of TS. This may occur through an increase in intracranial pressure causing hyperactivation of the cardiac sympathetic nervous system [68]. Hammer et al. [69] reported on the rapid appearance and disappearance of the electrocardiographic changes with perturbations of the nervous system. Sharkey et al. [70] reported on episodes of decerebrate posturing in a comatose patient who had sustained a closed head injury with LVWMA. With each episode, transient anterior ST segment elevation appeared followed by resolution of ST elevation and finally T-wave inversion. These findings suggest that these effects were due to neural rather than humoral factors.

Medical or surgical sympathetic antagonism and TS Propranolol, which is a beta-adrenoceptor antagonist, has shown cardioprotective effects in patients with subarachnoid hemorrhage [71]. Necrotic myocardial lesions were present in all patients who received placebo, whereas no necrotic lesions were observed in patients treated with propranolol, suggesting a cardioprotective effect of antagonism of sympathetic activation in the course of subarachnoid hemorrhage. Furthermore, preadmission treatment with beta-blockers in patients with aneurysmal subarachnoid hemorrhage was associated with a decreased incidence of neurogenic stunned myocardium [72]. Other investigators have reported on similar cardioprotective effects of beta-blockers in the course of subarachnoid hemorrhage [73]. ECG changes resembling those observed in the midapical pattern of TS and TS-like LVWMA have been induced in animal studies by brain and stellate ganglion stimulation, and experimental intracranial haemorrhage [60]. These changes could be prevented either by surgical (spinal cord transection or severing) or pharmacological (reserpine, propranolol) sympathectomy [1, 60]. Furthermore, Sharkey et al. [70] could interrupt cycles of anterior ST elevations during episodes of decerbrate posturing in a patient with a closed head injury and LVWMA by administering metoprolol and clonidine.

Prevalence of diabetes mellitus in patients with takotsubo syndrome A low prevalence of diabetes mellitus in TS patients has been reported by several investigators. In a review of 959 studies, Madias [74] reported that the prevalence of diabetes mellitus among patients with TS to be within the range $10.2-17 \%$, which was lower than the $26.9 \%$ found by the National Health and Nutritional Examination Survey (NHANES). Tornvall et al. [75] confirmed this finding in a recent register study where diabetes mellitus was significantly less common in TS $(6.5 \%)$ compared to ACS patients (19.8\%). Diabetes mellitus-induced autonomic neuropathy may lead to brain-heart disconnection and thus may have a protective effect against TS in situations with emotional or physical stress.

\section{Evidence for local cardiac sympathetic denervation in TS}

Signs of cardiac sympathetic denervation assessed by 123I-metaiodobenzylguanidine $\left({ }^{123} \mathrm{I}-\mathrm{MIBG}\right)$ scintigraphy [76] and by ${ }^{11} \mathrm{C}$ hydroxyephedrine positron emission tomography (PET) [77] have been demonstrated at LVWMA regions in patients with TS. Madias [78] reviewed 112 TS patients who underwent ${ }^{123} \mathrm{I}$-MIBG. The principle finding from the analysis was decreased regional uptake of ${ }^{123} \mathrm{I}-\mathrm{MIBG}$ in hypokinetic/akinetic left ventricular segments with increased washout of ${ }^{123} \mathrm{I}-\mathrm{MIBG}$.

\section{Norepinephrine seethe and spillover from the cardiac sympathetic nerve terminals}

Induction of brain death and subarachnoid haemorrhage in animal models and diverse types of intracranial diseases and injuries in humans have been reported to induce TSlike LVWMA [1]. Increased myocardial interstitial, but not plasma, norepinephrine has been demonstrated by Mertes et al. after brain death induction in pigs [79]. Naredi et al. [80] demonstrated increased in total-body norepinephrine concentrations during the acute stage of subarachnoid haemorrhage, suggesting massive sympathetic nervous system activation. Elevated norepinephrine levels in the coronary sinus in five patients with TS demonstrated by Kume et al. [81] suggests increased local myocardial catecholamine release. One further study has shown that sympathectomy, but not adrenalectomy, prevented LVWMA in baboons after subarachnoid haemorrhage, further supporting the role of local catecholamine release in the pathophysiology of the disease [82].

\section{Evidence of catecholamine myocarditis in TS}

Chemical myocarditis may be one phase in the course of myocardial pathological changes occurring in TS, most probably through local cardiac sympathetic overactivationdisruption and norepinephrine spillover $[60,83,84]$. In a typical TS patient, endomyocardial biopsy revealed myocarditis where catecholamine myocarditis could not be excluded 
[85]. During recent years, case series of typical TS with biopsy-proven myocarditis or findings consistent with myocarditis on cardiac magnetic resonance (CMR) imaging have been described [84]. In 2012, Neil et al. [86] reported on the extent of myocardial edema detected by CMR imaging, performed in the acute stage and after 3 months, in 32 patients with TS. They found that TS was associated with a slowly resolving global myocardial edema. When changes suggestive of myocarditis are detected by CMR imaging in patients with TS, they are usually constrained to the akinetic/hypokinetic regions of the left ventricle [87]. In a CMR imaging study of a large TS patient group, Eitel et al. [6] demonstrated myocardial edema in 162 of 199 patients (81\%) with a distinct transmural, midventricular to apical regional distribution pattern matching the distribution of the LVWMA. Focal or patchy nonischemic late gadolinium enhancement was detected in 22 of 239 patients (9\%). In the same study, 110 of $164(67 \%)$ patients who underwent inflammation assessment according to the Lake Louise consensus criteria for CMR diagnosis of myocardial inflammation/myocarditis had evidence of active inflammation. Of those patients, 75\% had concomitant pericardial effusion, providing supportive evidence of an inflammatory process in the acute phase of the disease.

\section{The distribution pattern of the regional ventricular wall motion abnormality in TS}

The LVWMA in TS has a characteristic systematized pattern. It affects the ventricular myocardium circumferentially with a sharp transition between the hypo/akinetic and the normal/hyperkinetic myocardial segments, resulting in a conspicuous left ventricular ballooning during systole [88]. The heart is densely innervated with sympathetic nerves which are distributed on a regional basis. The pattern of LVWMA in TS appears to follow the anatomical sympathetic innervation from the left and right stellate and caudal ganglia [89] (Fig. 2). Worth mentioning is that there are only two anatomical systems which may be involved in the LVWMA on a regional basis: the coronary arterial and the neural systems. Convincing evidence challenges the coronary arterial system as being involved in LVWMA in TS, thus making the neural system an attractive pathophysiological substrate [60]. Hence, the different patterns of TS are possibly seen due to involvement of different branches of the cardiac sympathetic system. To the best of our knowledge, the precise anatomical distribution of the various branches of the cardiac sympathetic nervous system is not known, which is necessary to specify the branch or branches of the cardiac sympathetic nerves involved in TS. Such data may facilitate categorization of the different patterns of TS (apical, midapical, midventricular, midbasal, basal, focal and global) according to the sympathetic branch involved
(Fig. 2) in a manner analogous to that of a coronary artery occlusion causing anterior, inferior, lateral, and true posterior myocardial infarction.

\section{Autonomic nervous system and TS}

Heart rate variability (HRV) analysis has been performed in both the acute phase and at follow-up of TS by several investigators [90]. The indices of HRV were markedly depressed within $48 \mathrm{~h}$ after hospital admission but normalized at the 3-month follow-up [91]. Bonnemeier et al. [92] reported significant differences in cardiac autonomic modulation and fractal organization of heart rate dynamics between apical and midventricular ballooning patterns of TS. The authors concluded that inhomogeneous efferent bilateral sympathetic coactivation and differences in reflex autonomic regulation may be the underlying pathophysiological mechanisms for apical and midventricular patterns of TS. Vaccaro et al. [93] reported that patients with TS in the subacute phase of the disease exhibited elevated sympathetic nervous system activity associated with a decrease in spontaneous baroreflex control of sympathetic activity. In contrast, Sverrisdottir et al. [94] found that patients with TS had a decrease in muscle sympathetic nerve activity compared with healthy matched controls. However, more than half of the subjects in this later study were studied in the recovery phase up to 6 months after their TS event. Impaired baroreflex control may play a role in the development of TS; even long after the initial episode, women with previous episode of TS have excessive sympathetic responsiveness and reduced parasympathetic modulation of their heart rate $[95,96]$. Worsening of chest pain and T-wave inversions on electrocardiogram have been reported in a patient with TS who received atropine because of bradycardia [97]. The withdrawal of the parasympathetic drive may thus exacerbate the sympathetic activity, resulting in worsening of the LVWMA. During follow-up of TS, Collste et al. [98] reported that mental stress performed more than 6 months after the acute event did not induce a significant difference in myocardial function or HRV response between TS and control subjects. However, Lazzeroni et al. [99] reported that compared to healthy subjects, TS patients, investigated more than 1 year after the acute event, showed blunted parasympathetic reactivation after exercise, thereby suggesting that vagal control of heart rate is abnormal in TS.

\section{Management of TS}

\section{Confirm the diagnosis of TS}

TS may be misdiagnosed as ACS because of the similarities in clinical presentation. TS should, therefore, be considered 
as a differential diagnosis in patients presenting with clinical features of ACS. TS may be triggered by, among others, intracranial hemorrhage or gastrointestinal bleedings and treating such patients with anticoagulation and fibrinolysis may result in life-threatening bleeding complications and death. Cardiogenic shock caused by LVOTO in TS may be misdiagnosed as cardiogenic shock due to extensive myocardial infarction and treated by catecholamine inotropics, which may result in augmentation of LVOTO and worsening of the cardiogenic shock with dismal consequences. Performing urgent coronary angiography, including left ventriculography, is essential to detect TS and to differentiate it from ACS because patients with TS have no coronary culprit lesion to explain the entire LVWMA seen in TS. Furthermore, the association between ACS and TS should not be missed since ACS may trigger TS [100]. In women presenting with ACS without angiographically demonstrable obstructive coronary artery disease, other mechanisms of myocardial infarction with TS as coronary ulceration with peripheral embolization, transient coronary vasospasm, or spontaneous coronary artery dissection should be considered [40, 101, 102]. In patients with severe comorbidities, where invasive coronary angiography may be associated with risks of complications, noninvasive cardiac computed tomography angiography may be considered [40]. Cardiac imaging studies, especially echocardiography, should be performed as early as possible during patient presentation and should be repeated because the LVWMA may resolve in hours to weeks [100] (Fig. 2). Echocardiography is also valuable to identify the distribution of LVWMA, involvement of the right ventricle, and complications of TS as left ventricular thrombus and LVOTO. CMR imaging provides invaluable information on the morphology of TS, involvement of the right ventricle, myocardial edema, and complications of TS as left ventricular thrombus. Furthermore, CMR imaging can differentiate TS from diseases which cause irreversible myocardial damage, such as myocardial infarction and myocarditis [6].

\section{Treatment of the precipitating and predisposing diseases}

In almost one third of the patients, TS is triggered by physical stress, including serious medical or surgical conditions as sepsis, intracranial diseases, pheochromocytoma, and acute exacerbation of chronic obstructive pulmonary diseases [8, 15,103 ]. In a study comprised of 1750 patients [4], 36\% of TS patients had physical stress as a trigger. These diseases may contribute significantly to the increase in mortality seen in patients with TS [104]. Furthermore, in undiagnosed pheochromocytoma [75], there is an increased risk of recurrent TS, sometimes with a dramatic clinical presentation including a compromised hemodynamic situation $[15,105]$. Proper investigations for predisposing diseases including appropriate treatment in addition to treatment of TS is imperative and may have an impact on improving the prognosis and in preventing TS recurrence (Fig. 5).

\section{Treatment of TS}

\section{Treatment during the acute stage}

A characteristic feature of TS is the spontaneous resolution of LVWMA in hours to weeks $[4,8,100]$ (Fig. 1). Consequently, treatment in the acute stage should be supportive and focus on appropriate treatment of complications [4, 9]. There are neither controlled studies nor guidelines on how to treat TS. In mild cases, in addition to supportive therapy, beta-blockers and aspirin may be considered $[9,106]$. In cases complicated by heart failure, conventional treatment with angiotensin-converting enzymes (ACE) and/or angiotensin receptor blockers, beta-blockers, and diuretics is often initiated $[4,107]$. However, one study found no association between early beta-blocker use and in-hospital mortality in patients with TS [108]. TS patients should be monitored by telemetry and arrhythmias should be treated accordingly [9]. One serious complication of TS is thromboembolism [109]. In patients with extensive midapical ballooning and documented thrombus in the left ventricle or embolic complications, anticoagulation is recommended for 2-3 months or until resolution of LVWMA and left ventricular thrombus has been confirmed by echocardiography $[9,109]$. Betablockers, theoretically, may have a protective effect against cardiac rupture, which also is a recognized complication of TS [110].

\section{Treatment of cardiogenic shock in TS}

Cardiogenic shock is an important and life-threatening complication in TS $[4,8,15]$. The crucial step in treatment is to detect whether the hypotension is caused by LVOTO or primary pump failure [111]. In LVOTO, which may be associated with systolic anterior motion (SAM) of the mitral valve anterior leaflet and mitral regurgitation, catecholamine inotropics such as adrenaline and noradrenaline, dopamine, milrinone, and isoproterenol are contraindicated. Treatment with diuretics, nitroglycerine, and an intraaortic balloon pump should be avoided because of the risk of aggravation of LVOTO. The suggested treatment in LVOTO is intravenous fluid and parenteral beta-blockers, which increases cardiac filling and suppresses the basal hypercontractility, thereby reducing LVOTO [112]. In patients intolerant to intravenous fluid and beta-blockers, phenylphrine may be effective by increasing the afterload and the left ventricular size. In primary pump failure, treatment with venoarterial extracorporeal membrane oxygenation or a left ventricular 


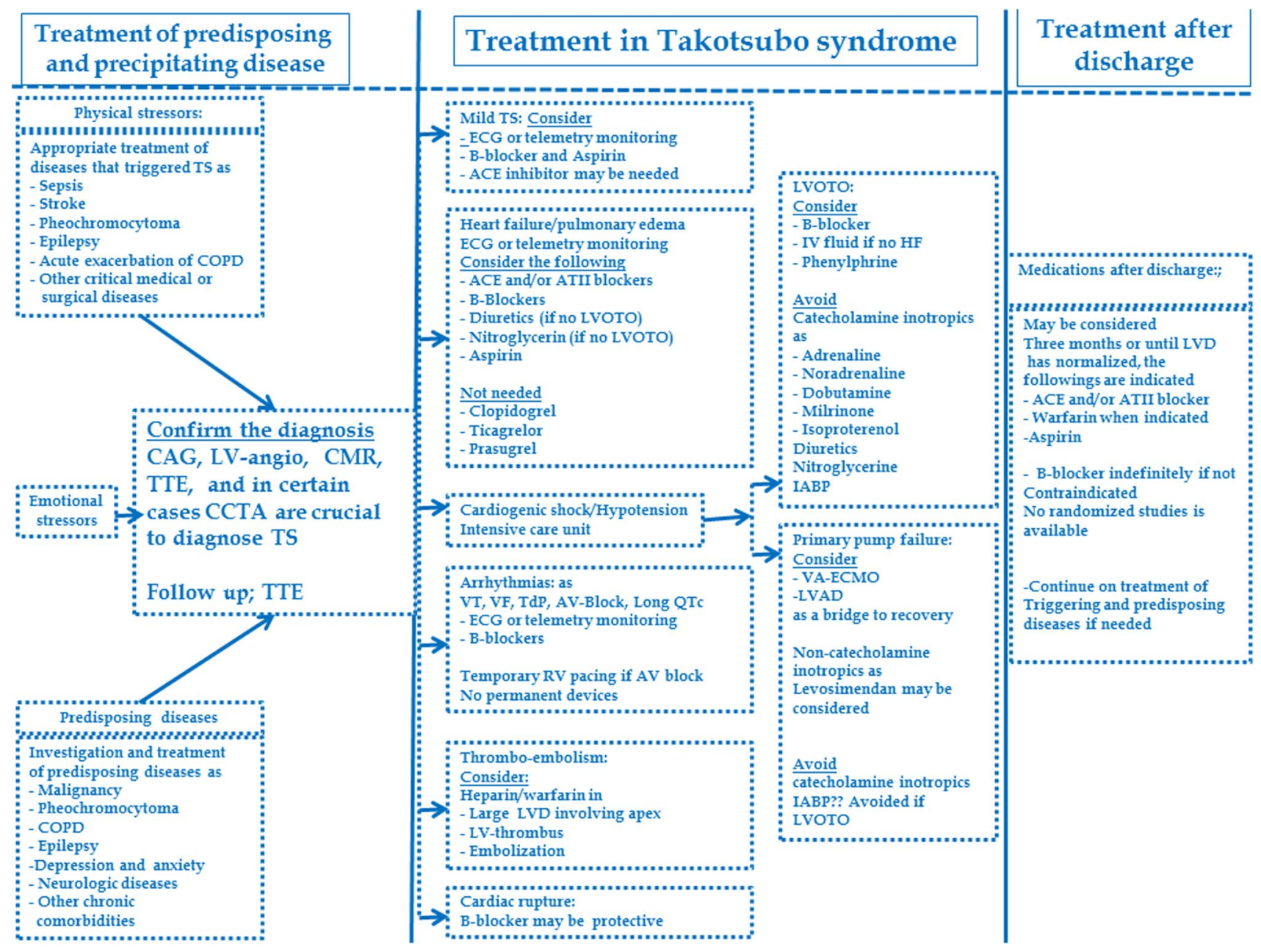

Fig. 5 Management of takotsubo syndrome. ATII angiotensin II, $C A G$ coronary angiography, $C O P D$ chronic obstructive pulmonary disease, $E C G$ electrocardiogram, $I A B P$ intra-aortic balloon pump, $H F$ heart failure, $L V$ left ventricular, $L V A D$ left ventricular assist device, $L V D$ left ventricular dysfunction, LVOTO left ventricular outlet tract obstruction, TdP Torsades de pointes, TS takotsubo syndrome, TTE transthoracic echocardiography, $V A-E C M O$ venoarterial-extracorporeal membrane oxygenation, $V F$ ventricular fibrillation, $V T$ ventricular tachycardia assist device should be considered as a bridge to recovery [9]. Noncatecholamine inotropics such as levosimendan [113] may also be considered in primary pump failure in TS but catecholamine-based inotropics should be avoided [9].

\section{Treatment after discharge}

There are no randomized studies on long-term treatment in TS. Observational studies have shown that the use of ACE inhibitors or angiotensin receptor blockers was associated with improved survival up to 1 year after the acute event. Such survival benefits have not been observed with betablockers [4]. As mentioned above, in cases of left ventricular thromboembolism, treatment with warfarin should be continued until resolution of the LVWMA and left ventricular thrombus. Appropriate treatment and prophylaxis of the precipitating and predisposing diseases is vital to prevent recurrence of the disease.

Open Access This article is distributed under the terms of the Creative Commons Attribution 4.0 International License (http://creativecommons.org/licenses/by/4.0/), which permits unrestricted use, distribution, and reproduction in any medium, provided you give appropriate credit to the original author(s) and the source, provide a link to the Creative Commons license, and indicate if changes were made.

\section{References}

1. YH S, De Palma R (2016) Contemporary review on the pathogenesis of takotsubo syndrome: the heart shedding tears: norepinephrine churn and foam at the cardiac sympathetic nerve terminals. Int J Cardiol 228:528-536 
2. YH S, Yamasaki K (2013) History of takotsubo syndrome: is the syndrome really described as a disease entity first in 1990 ? Some inaccuracies. Int J Cardiol 166:736-737

3. Dote K, Sato H, Tateishi H, Uchida T, Ishihara M (1991) Myocardial stunning due to simultaneous multivessel coronary spasms: a review of 5 cases. J Cardiol 21:203-214

4. Templin C, Ghadri JR, Diekmann J, Napp LC, Bataiosu DR, Jaguszewski M et al (2015) Clinical features and outcomes of takotsubo (stress) cardiomyopathy. N Engl J Med 373:929-938

5. YH S, Tornvall P, Tornerud M, Henareh L (2013) Capecitabine caused cardiogenic shock through induction of global takotsubo syndrome. Cardiovasc Revasc Med Incl Mol Interv 14:57-61

6. Eitel I, von Knobelsdorff-Brenkenhoff F, Bernhardt P, Carbone I, Muellerleile K, Aldrovandi A et al (2011) Clinical characteristics and cardiovascular magnetic resonance findings in stress (takotsubo) cardiomyopathy. JAMA J Am Med Assoc 306:277-286

7. Cramer MJ, De Boeck B, Melman PG, Sieswerda GJ (2007) The 'broken heart' syndrome: what can be learned from the tears and distress? Neth Heart J Mon J Neth Soc Cardiol Neth Heart Found 15:283-285

8. Sharkey SW, Windenburg DC, Lesser JR, Maron MS, Hauser RG, Lesser JN et al (2010) Natural history and expansive clinical profile of stress (tako-tsubo) cardiomyopathy. J Am Coll Cardiol 55:333-341

9. Lyon AR, Bossone E, Schneider B, Sechtem U, Citro R, Underwood SR et al (2016) Current state of knowledge on takotsubo syndrome: a Position Statement from the Taskforce on takotsubo Syndrome of the Heart Failure Association of the European Society of Cardiology. Eur J Heart Fail 18:8-27

10. Prasad A, Lerman A, Rihal CS (2008) Apical ballooning syndrome (tako-tsubo or stress cardiomyopathy): a mimic of acute myocardial infarction. Am Heart J 155:408-417

11. Nascimento FO, Larrauri-Reyes MC, Santana O, Perez-Caminero M, Lamas GA (2013) Comparison of stress cardiomyopathy in Hispanic and non-Hispanic patients. Rev Esp Cardiol (Engl Ed) 66:67-68

12. Akashi YJ, Nef HM, Lyon AR (2015) Epidemiology and pathophysiology of takotsubo syndrome. Nat Rev Cardiol 12:387-397

13. Minhas AS, Hughey AB, Kolias TJ (2015) Nationwide trends in reported incidence of takotsubo cardiomyopathy from 2006 to 2012. Am J Cardiol 116:1128-1131

14. Murugiah K, Wang Y, Desai NR, Spatz ES, Nuti SV, Dreyer RP et al (2016) Trends in short- and long-term outcomes for takotsubo cardiomyopathy among medicare fee-for-service beneficiaries, 2007 to 2012. JACC Heart Fail 4:197-205

15. YH S (2016) Clinical features and outcome of pheochromocytoma-induced takotsubo syndrome: analysis of 80 published cases. Am J Cardiol 117:1836-1844

16. Park JH, Kang SJ, Song JK, Kim HK, Lim CM, Kang DH et al (2005) Left ventricular apical ballooning due to severe physical stress in patients admitted to the medical ICU. Chest 128:296-302

17. Singh K, Carson K, Usmani Z, Sawhney G, Shah R, Horowitz J (2014) Systematic review and meta-analysis of incidence and correlates of recurrence of takotsubo cardiomyopathy. Int J Cardiol 174:696-701

18. Sato H, Tateishi H, Uchida T, Dote K, Ishihara M, Sasaki K (1990) Takotsubo-type cardiomyopathy due to multivessel spasm. In: Kodama K, Haze K, Hori M (eds) Clinical aspect of myocardial injury: from ischemia to heart failure. Kagakuhyouronsha Publishing Co, Tokyo, pp 56-64

19. Abraham J, Mudd JO, Kapur NK, Klein K, Champion HC, Wittstein IS (2009) Stress cardiomyopathy after intravenous administration of catecholamines and beta-receptor agonists. J Am Coll Cardiol 53:1320-1325
20. YH S (2016) Clinical features and outcome of epinephrineinduced takotsubo syndrome: analysis of 33 published cases. Cardiovasc Revasc Med Incl Mol Interv 17:450-455

21. Vitale C, Rosano GM, Kaski JC (2016) Role of coronary microvascular dysfunction in takotsubo cardiomyopathy. Circ J Off J Jpn Circ Soc 80:299-305

22. Fazio G, Sarullo FM, Novo G, Evola S, Lunetta M, Barbaro G et al (2010) Tako-tsubo cardiomyopathy and microcirculation. J Clin Monit Comput 24:101-105

23. Sharkey SW, Lesser JR, Menon M, Parpart M, Maron MS, Maron BJ (2008) Spectrum and significance of electrocardiographic patterns, troponin levels, and thrombolysis in myocardial infarction frame count in patients with stress (tako-tsubo) cardiomyopathy and comparison to those in patients with STelevation anterior wall myocardial infarction. Am J Cardiol 101:1723-1728

24. Abdelmoneim SS, Mankad SV, Bernier M, Dhoble A, Hagen ME, Ness SA et al (2009) Microvascular function in takotsubo cardiomyopathy with contrast echocardiography: prospective evaluation and review of literature. J Am Soc Echocardiogr Off Publ Am Soc Echocardiogr 22:1249-1255

25. Collste O, Tornvall P, Alam M, Frick M (2015) Coronary flow reserve during dobutamine stress in takotsubo stress cardiomyopathy. BMJ Open 5:e007671

26. Ibanez B, Navarro F, Cordoba M, MA P, Farre J (2005) Takotsubo transient left ventricular apical ballooning: is intravascular ultrasound the key to resolve the enigma? Heart 91:102-104

27. Haghi D, Roehm S, Hamm K, Harder N, Suselbeck T, Borggrefe $M$ et al (2010) Takotsubo cardiomyopathy is not due to plaque rupture: an intravascular ultrasound study. Clin Cardiol 33:307-310

28. Delgado GA, Truesdell AG, Kirchner RM, Zuzek RW, Pomerantsev EV, Gordon PC et al (2011) An angiographic and intravascular ultrasound study of the left anterior descending coronary artery in takotsubo cardiomyopathy. Am J Cardiol 108:888-891

29. Kim S, Yu A, Filippone LA, Kolansky DM, Raina A (2010) Inverted-Takotsubo pattern cardiomyopathy secondary to pheochromocytoma: a clinical case and literature review. Clin Cardiol 33:200-205

30. Reuss CS, Lester SJ, Hurst RT, Askew JW, Nager P, Lusk J et al (2007) Isolated left ventricular basal ballooning phenotype of transient cardiomyopathy in young women. Am J Cardiol 99:1451-1453

31. Ikeda E, Hisamatsu K, Kijima Y, Mizoguchi H, Urakawa S, Kimura H et al (2009) Morphologically unique feature of recurrent ampulla (takotsubo) cardiomyopathy. Circ J 73:371-375

32. Hoyt J, Lerman A, Lennon RJ, Rihal CS, Prasad A (2010) Left anterior descending artery length and coronary atherosclerosis in apical ballooning syndrome (takotsubo/stress induced cardiomyopathy). Int J Cardiol 145:112-115

33. Ueda H, Hosokawa Y, Tsujii U, Miyawaki M, Mitsusada N, Yasuga Y et al (2011) An autopsy case of left ventricular apical ballooning probably caused by pheochromocytoma with persistent ST-segment elevation. Int J Cardiol 149:e50-e52

34. Akashi YJ, Sakakibara M, Miyake F (2002) Reversible left ventricular dysfunction "takotsubo" cardiomyopathy associated with pneumothorax. Heart 87:E1

35. Samuels MA (1987) Neurogenic heart disease: a unifying hypothesis. Am J Cardiol 60:15J-19J

36. Samuels MA (2007) The brain-heart connection. Circulation 116:77-84

37. Nef HM, Mollmann H, Kostin S, Troidl C, Voss S, Weber M et al (2007) Tako-tsubo cardiomyopathy: intraindividual structural analysis in the acute phase and after functional recovery. Eur Heart J 28:2456-2464 
38. YH S, Jernberg T (2011) Bromocriptine-induced coronary spasm caused acute coronary syndrome, which triggered its own clinical twin-takotsubo syndrome. Cardiology 119:1-6

39. YH S, Henareh L (2013) Spontaneous coronary artery dissection triggered post-ischemic myocardial stunning and takotsubo syndrome: two different names for the same condition. Cardiovasc Revasc Med Incl Mol Interv 14:109-112

40. S YH, Themudo R, Maret E (2017) Spontaneous coronary artery dissection and takotsubo syndrome: the chicken or the egg causality dilemma. Catheter Cardiovasc Interv Off J Soc Card Angiogr Interv 89(7):1215-1218

41. El Mahmoud R, Mansencal N, Pilliere R, Leyer F, Abbou N, Michaud P et al (2008) Prevalence and characteristics of left ventricular outflow tract obstruction in tako-tsubo syndrome. Am Heart J 156:543-548

42. Agarwal V, Kant G, Hans N, Messerli FH (2011) Takotsubolike cardiomyopathy in pheochromocytoma. Int $\mathrm{J}$ Cardiol 153:241-248

43. Nazir S, Lohani S, Tachamo N, Ghimire S, Poudel DR, Donato A (2017) Takotsubo cardiomyopathy associated with epinephrine use: a systematic review and meta-analysis. Int J Cardiol 229:67-70

44. Haghi D, Athanasiadis A, Papavassiliu T, Suselbeck T, Fluechter $\mathrm{S}$, Mahrholdt $\mathrm{H}$ et al (2006) Right ventricular involvement in takotsubo cardiomyopathy. Eur Heart J 27:2433-2439

45. Wittstein IS, Thiemann DR, Lima JA, Baughman KL, Schulman SP, Gerstenblith G et al (2005) Neurohumoral features of myocardial stunning due to sudden emotional stress. N Engl J Med 352:539-548

46. YH S (2017) Serotonin norepinephrine re-uptake inhibitor (SNRI)-, selective norepinephrine reuptake inhibitor (S-NRI)-, and exogenously administered norepinephrine-induced takotsubo syndrome: analysis of published cases. Int J Cardiol 231:228-233

47. Gianni M, Dentali F, Grandi AM, Sumner G, Hiralal R, Lonn E (2006) Apical ballooning syndrome or takotsubo cardiomyopathy: a systematic review. Eur Heart J 27:1523-1529

48. Madhavan M, Borlaug BA, Lerman A, Rihal CS, Prasad A (2009) Stress hormone and circulating biomarker profile of apical ballooning syndrome (takotsubo cardiomyopathy): insights into the clinical significance of B-type natriuretic peptide and troponin levels. Heart 95:1436-1441

49. YH S, Henareh L (2015) Plasma catecholamine levels in patients with takotsubo syndrome: implications for the pathogenesis of the disease. Int J Cardiol 181:35-38

50. Coupez E, Eschalier R, Pereira B, Pierrard R, Souteyrand G, Clerfond G et al (2014) A single pathophysiological pathway in takotsubo cardiomyopathy: catecholaminergic stress. Archives Cardiovasc Dis 107:245-252

51. Wickboldt N, Pache JC, Dietrich PY, Toso C, Gallay C, Brochard L et al (2012) Takotsubo syndrome secondary to adrenal adenocarcinoma: cortisol as a possible culprit. Am J Respir Crit Care Med 186:1061-1062

52. Sakihara S, Kageyama K, Nigawara T, Kidani Y, Suda T (2007) Ampulla (takotsubo) cardiomyopathy caused by secondary adrenal insufficiency in ACTH isolated deficiency. Endocr J 54:631-636

53. Kastaun S, Schwarz NP, Juenemann M, Yeniguen M, Nef HM, Moellmann H et al (2014) Cortisol awakening and stress response, personality and psychiatric profiles in patients with takotsubo cardiomyopathy. Heart 100:1786-1792

54. Smeijers L, Szabo BM, van Dammen L, Wonnink W, Jakobs BS, Bosch JA et al (2015) Emotional, neurohormonal, and hemodynamic responses to mental stress in tako-tsubo cardiomyopathy. Am J Cardiol 115:1580-1586

55. Lyon AR, Rees PS, Prasad S, Poole-Wilson PA, Harding SE (2008) Stress (takotsubo) cardiomyopathy-a novel pathophysiological hypothesis to explain catecholamine-induced acute myocardial stunning. Nat Clin Pract Cardiovasc Med 5:22-29

56. Paur H, Wright PT, Sikkel MB, Tranter MH, Mansfield C, O'Gara P et al (2012) High levels of circulating epinephrine trigger apical cardiodepression in a beta2-adrenergic receptor/Gidependent manner: a new model of takotsubo cardiomyopathy. Circulation 126:697-706

57. Redfors B, Ali A, Shao Y, Lundgren J, Gan LM, Omerovic E (2014) Different catecholamines induce different patterns of takotsubo-like cardiac dysfunction in an apparently afterload dependent manner. Int J Cardiol 174(2):330-336

58. YH S (2015) The pathogenesis of reversible T-wave inversions or large upright peaked T-waves: sympathetic T-waves. Int J Cardiol 191:237-243

59. YH S (2012) Insights into the pathogenesis of takotsubo syndrome, which with persuasive reasons should be regarded as an acute cardiac sympathetic disease entity. ISRN Cardiol 2012:593735

60. YH S (2014) Acute cardiac sympathetic disruption in the pathogenesis of the takotsubo syndrome: a systematic review of the literature to date. Cardiovasc Revasc Med Incl Mol Interv 15:35-42

61. Rees WD, Lutkins SG (1967) Mortality of bereavement. BMJ 4:13-16

62. Pavin D, Le Breton H, Daubert C (1997) Human stress cardiomyopathy mimicking acute myocardial syndrome. Heart 78:509-511

63. Finsterer J, Wahbi K (2014) CNS disease triggering takotsubo stress cardiomyopathy. Int J Cardiol 177:322-329

64. YH S (2011) Takotsubo syndrome triggered by an epileptic seizure may be the cause of abnormal cardiac repolarization seen in patients with epilepsy. Epilepsia 52:654-655

65. YH S, Lindroos M (2011) Cerebellar haemorrhage triggered takotsubo-like left ventricular dysfunction syndrome. Int J Cardiol 151:e85-e87

66. Lopez Chiriboga AS, Yoon JW, Freeman WD, Odunukan OW, Cheshire WP Jr (2016) Takotsubo cardiomyopathy in the setting of acute hydrocephalus secondary to neurocysticercosis. Clin Auton Res Off J Clin Auton Res Soc 26:235-241

67. Quick S, Speiser U, Richter N, Youssef A, Waessnig N, Strasser RH et al (2015) Transient global amnesia and broken heart syndrome: two faces of one pathology. Clin Auton Res Off J Clin Auton Res Soc 25:189-191

68. Berman M, Ali A, Ashley E, Freed D, Clarke K, Tsui S et al (2010) Is stress cardiomyopathy the underlying cause of ventricular dysfunction associated with brain death? J Heart Lung Transpl Off Publ Int Soc Heart Transpl 29:957-965

69. Hammer WJ, Luessenhop AJ, Weintraub AM (1975) Observations on the electrocardiographic changes associated with subarachnoid hemorrhage with special reference to their genesis. Am J Med 59:427-433

70. Sharkey SW, Shear W, Hodges M, Herzog CA (1998) Reversible myocardial contraction abnormalities in patients with an acute noncardiac illness. Chest 114:98-105

71. Neil-Dwyer G, Walter P, Cruickshank JM, Doshi B, O'Gorman $P$ (1978) Effect of propranolol and phentolamine on myocardial necrosis after subarachnoid haemorrhage. Br Med J 2:990-992

72. Liang CW, Chen R, Macri E, Naval N (2013) Preadmission betablockers are associated with decreased incidence of neurogenic stunned myocardium in aneurysmal subarachnoid hemorrhage. J Stroke Cerebrovasc Dis Off J Natl Stroke Assoc 22:601-607

73. Pinnamaneni S, Dutta T, Melcer J, Aronow WS (2015) Neurogenic stress cardiomyopathy associated with subarachnoid hemorrhage. Future Cardiol 11:77-87

74. Madias JE (2015) Low prevalence of diabetes mellitus in patients with takotsubo syndrome: a plausible 'protective' effect with pathophysiologic connotations. Eur Heart J Acute Cardiovasc Care 5(2):164-170 
75. Tornvall P, Collste O, Ehrenborg E, Jarnbert-Petterson H (2016) A case-control study of risk markers and mortality in takotsubo stress cardiomyopathy. J Am Coll Cardiol 67:1931-1936

76. Marfella R, Barbieri M, Sardu C, Rizzo MR, Siniscalchi M, Paolisso P, et al. Effects of alpha-lipoic acid therapy on sympathetic heart innervation in patients with previous experience of transient takotsubo cardiomyopathy. J Cardiol. 2015

77. Prasad A, Madhavan M, Chareonthaitawee P (2009) Cardiac sympathetic activity in stress-induced (takotsubo) cardiomyopathy. Nat Rev Cardiol 6:430-434

78. Madias JE (2015) Do we need MIBG in the evaluation of patients with suspected takotsubo syndrome? Diagnostic, prognostic, and pathophysiologic connotations. Int J Cardiol 203:783-784

79. Mertes PM, Carteaux JP, Jaboin Y, Pinelli G, el Abassi K, Dopff $C$ et al (1994) Estimation of myocardial interstitial norepinephrine release after brain death using cardiac microdialysis. Transplantation 57:371-377

80. Naredi S, Lambert G, Eden E, Zall S, Runnerstam M, Rydenhag B et al (2000) Increased sympathetic nervous activity in patients with nontraumatic subarachnoid hemorrhage. Stroke J Cereb Circ 31:901-906

81. Kume T, Kawamoto T, Okura H, Toyota E, Neishi Y, Watanabe $\mathrm{N}$ et al (2008) Local release of catecholamines from the hearts of patients with tako-tsubo-like left ventricular dysfunction. Circ J Off J Jpn Circ Soc 72:106-108

82. Novitzky D, Wicomb WN, Cooper DK, Rose AG, Reichart B (1986) Prevention of myocardial injury during brain death by total cardiac sympathectomy in the Chacma baboon. Ann Thorac Surg 41:520-524

83. YH S (2015) Myocarditis is an essential feature rather than an exclusion criterion for takotsubo syndrome: case report. Int J Cardiol 187:304-306

84. YH S (2014) Myocarditis and takotsubo syndrome: are they mutually exclusive? Int J Cardiol 177:149-151

85. Case records of the Massachusetts General Hospital (1986) Weekly clinicopathological exercises. Case 18-1986. A 44-year-old woman with substernal pain and pulmonary edema after severe emotional stress. N Engl J Med 314:1240-1247

86. Neil C, Nguyen TH, Kucia A, Crouch B, Sverdlov A, Chirkov $Y$ et al (2012) Slowly resolving global myocardial inflammation/ oedema in tako-tsubo cardiomyopathy: evidence from T2-weighted cardiac MRI. Heart 98:1278-1284

87. Dastidar AG, Frontera A, Palazzuoli A, Bucciarelli-Ducci C (2015) Takotsubo cardiomyopathy: unravelling the malignant consequences of a benign disease with cardiac magnetic resonance. Heart Fail Rev 20(4):415-421

88. Fujikawa M, Iwasaka J, Oishi C, Ueyama T, Park H, Yamamoto Y et al (2008) Three-dimensional echocardiographic assessment of left ventricular function in takotsubo cardiomyopathy. Heart Vessels 23:214-216

89. Randall WC, Szentivanyi M, Pace JB, Wechsler JS, Kaye MP (1968) Patterns of sympathetic nerve projections onto the canine heart. Circ Res 22:315-323

90. Wittstein IS (2016) The sympathetic nervous system in the pathogenesis of takotsubo syndrome. Heart Fail Clin 12:485-498

91. Ortak J, Khattab K, Barantke M, Wiegand UK, Bansch D, Ince H et al (2009) Evolution of cardiac autonomic nervous activity indices in patients presenting with transient left ventricular apical ballooning. Pacing Clin Electrophysiol PACE 32(Suppl 1):S21-S25

92. Bonnemeier H, Demming T, Weidtmann B, Ortak J, Burgdorf C, Reppel M et al (2010) Differential heart rate dynamics in transient left ventricular apical and midventricular ballooning. Heart Rhythm Off J Heart Rhythm Soc 7:1825-1832

93. Vaccaro A, Despas F, Delmas C, Lairez O, Lambert E, Lambert $\mathrm{G}$ et al (2014) Direct evidences for sympathetic hyperactivity and baroreflex impairment in Tako Tsubo cardiopathy. PLoS One 9:e93278
94. Sverrisdottir YB, Schultz T, Omerovic E, Elam M (2012) Sympathetic nerve activity in stress-induced cardiomyopathy. Clin Auton Res Off J Clin Auton Res Soc 22:259-264

95. Norcliffe-Kaufmann L, Kaufmann H, Martinez J, Katz SD, Tully L, Reynolds HR (2016) Autonomic findings in takotsubo cardiomyopathy. Am J Cardiol 117:206-213

96. Norcliffe-Kaufmann LJ, Reynolds HR (2011) Afferent baroreflex failure and tako-tsubo cardiomyopathy. Clin Auton Res Off J Clin Auton Res Soc 21:1-2

97. Sandhu G, Servetnyk Z, Croitor S, Herzog E (2010) Atropine aggravates signs and symptoms of takotsubo cardiomyopathy. Am J Emerg Med 28(258):e5-e7

98. Collste O, Tornvall P, Sundin O, Alam M, Frick M (2014) No myocardial vulnerability to mental stress in takotsubo stress cardiomyopathy. PLoS One 9:e93697

99. Lazzeroni D, Bini M, Castiglioni P, Moderato L, Ciraci C, Camaiora $\mathrm{U}$ et al (2017) Autonomic function in takotsubo syndrome long after the acute phase. Int J Cardiol 231:222-224

100. YH S (2015) Takotsubo syndrome triggered by acute coronary syndrome in a cohort of 20 patients: an often missed diagnosis. Int J Cardiol Res 02:28-33

101. Reynolds HR, Srichai MB, Iqbal SN, Slater JN, Mancini GB, Feit F et al (2011) Mechanisms of myocardial infarction in women without angiographically obstructive coronary artery disease. Circulation 124:1414-1425

102. YH S, Bohm F (2016) The causal link between spontaneous coronary artery dissection and takotsubo syndrome: a case presented with both conditions. Int J Cardiol 203:828-831

103. Burgdorf C, Kurowski V, Bonnemeier H, Schunkert H, Radke PW (2008) Long-term prognosis of the transient left ventricular dysfunction syndrome (tako-tsubo cardiomyopathy): focus on malignancies. Eur J Heart Fail 10:1015-1019

104. YH S (2016) Long-term excess mortality in takotsubo syndrome: is it justified to charge takotsubo for the excess long-term mortality? Eur J Heart Fail 18:878

105. YH S (2015) Recurrent takotsubo syndrome triggered by undiagnosed pheochromocytoma. Int J Cardiol 187:369-371

106. Dias A, Franco E, Koshkelashvili N, Bhalla V, Pressman GS, Hebert K et al (2016) Antiplatelet therapy in takotsubo cardiomyopathy: does it improve cardiovascular outcomes during index event? Heart Vessels 31:1285-1290

107. Brunetti ND, Santoro F, De Gennaro L, Correale M, Gaglione A, Di Biase $\mathrm{M}$ et al (2017) Combined therapy with beta-blockers and ACE-inhibitors/angiotensin receptor blockers and recurrence of takotsubo (stress) cardiomyopathy: a meta-regression study. Int J Cardiol 230:281-283

108. Isogai T, Matsui H, Tanaka H, Fushimi K, Yasunaga H (2016) Early beta-blocker use and in-hospital mortality in patients with takotsubo cardiomyopathy. Heart 102:1029-1035

109. El-Battrawy I, Borggrefe M, Akin I (2016) Takotsubo syndrome and embolic events. Heart Fail Clin 12:543-550

110. Kumar S, Kaushik S, Nautiyal A, Choudhary SK, Kayastha BL, Mostow N et al (2011) Cardiac rupture in takotsubo cardiomyopathy: a systematic review. Clin Cardiol 34:672-676

111. Sharkey SW, Pink VR, Lesser JR, Garberich RF, Maron MS, Maron BJ (2015) Clinical profile of patients with high-risk tako-tsubo cardiomyopathy. Am J Cardiol 116:765-772

112. Migliore F, Bilato C, Isabella G, Iliceto S, Tarantini G (2010) Haemodynamic effects of acute intravenous metoprolol in apical ballooning syndrome with dynamic left ventricular outflow tract obstruction. Eur J Heart Fail 12:305-308

113. Santoro F, Ieva R, Ferraretti A, Ienco V, Carpagnano G, Lodispoto $\mathrm{M}$ et al (2013) Safety and feasibility of levosimendan administration in takotsubo cardiomyopathy: a case series. Cardiovasc Ther 31:e133-e137 